\title{
Study on the Transformation from Local Universities to Applied Technology Universities
}

\author{
Yanlin Yin, Rui Han
}

Heilongjiang University of Technology, Jixi, Heilongjiang, 158100

Keywords: Transformation Method, Local University, Applied Technology Universities

\begin{abstract}
The transformation from local universities to applied technology universities aims to integrate and optimize the resources for running schools and enterprises. The core of the talent training mode transformation is to build an application-based curriculum system. The transformation of discipline and specialty construction should lay emphasis on the development of curriculum resources and construction, in order to achieve the update of teaching content; transformation of teaching staff is to promote the development of double-qualified teachers through the construction of quality standards and incentives. This is the basic problem in the transition of local undergraduate colleges and universities to the applied technology universities.
\end{abstract}

\section{Introduction}

Since the beginning of this century, the development of higher education in our country has brought the tendency of homogeneity with the rise of the new local undergraduate colleges and universities. The key to solving this problem is to strengthen the classified management of higher education. However, the implementation of classification management can not make sudden progress. Based on the overall innovation of institutional system, we must reconstruct the operational order of higher education from a fundamental point and guide higher schools to take the path of regional special development so as to jointly promote the overall structure and function of higher education. In June 2013, under the guidance of the Ministry of Education, Tianjin Polytechnic Normal University initiated the establishment of the Union of Applied Technology Universities (colleges) and set up a local college research center, opening the curtain for the transformation and development of new local undergraduate colleges. In April 2014, in order to explore the road to construction of an applied technology university with Chinese characteristics, the "International Forum on the Integration of Production and Education", sponsored by the University of Applied Science and Technology and held by 178 colleges and universities, was held in Henan Province. The forum published "Building Chinese Characteristics Applied Technology University "as the theme of" Zhumadian consensus. " In May 2014, in order to implement the strategic plan of the State Council on accelerating the establishment of a modern vocational education system and guiding the transformation of a number of general undergraduate colleges to applied technology-based colleges and universities, the Ministry of Education recently launched the Guiding Opinion on the Transformation and Development of Local Undergraduate Colleges and Universities Draft), for the University of Applied Technology pointed out the direction of construction [1].

\section{Local universities need to transform to the applied technology universities}

The transformation from local undergraduate colleges to applied science and technology universities is not only the need of social and economic development mode transformation and industrial restructuring and upgrading, but also a natural extension and deduction of its internal logic, which has aroused great concern from all walks of life and has formed an irreversible trend of development. With the in-depth integration of informatization and industrialization, the industrial structure of our country is constantly optimized and adjusted and transformed and upgraded. The decay of labor-intensive and low-tech industries, the proliferation of technology-intensive and 
high-tech industries have made high-tech, high-tech, high-knowledge, high value-added and highly integrated industries the notable features of the future industry. In 2013, the industrial restructuring and upgrading showed a new change. For the first time, the gross value of service output surpassed the rapid growth in emerging industries and emerging industries such as secondary industry, e-commerce, biomedicine and equipment manufacturing. The upgrading and upgrading of the industrial structure has increased the diverse needs of technical personnel who master modern science and technology and receive systematic skills training in terms of quantity, level and structure. At present, the supply of all kinds of high-tech application talents in our country is seriously inadequate and has become one of the major bottlenecks that restrict the readjustment and upgrading of China's industrial structure. Some studies show that at present, China's senior engineering, senior technicians and senior engineers and other technology-based personnel, seeking magnifications were as high as $2.34,2.25,2$ (3). If you blindly follow the tradition of running academic schools, personnel training will be severely out of line with the needs of economic and social development. Therefore, the transformation of local undergraduate colleges and universities has become a realistic demand for the transformation of local higher education in the transformation and upgrading of regional social economy [2].

With the expansion of enrollment in colleges and universities in China, the level of higher education, the structure of science and various specifications, the total amount of types of talents and the actual needs of society there is a dislocation. On the one hand, graduates find it hard to find employment; on the other hand, many enterprises find it difficult to find the talents they need. Statistics show that in 2013 the employment rate of university graduates nationwide was $71.9 \%$. Among them, the implementation rate of vocational colleges and universities was the highest, 78.1\%; followed by "211" (including "985") key universities, accounting for 75.5\%; Compared with the developed countries, there is a serious imbalance in the structure of higher education in our country. Therefore, the construction of applied technology university has become the focal point of the structural adjustment of higher education. To achieve the transformation from training academic professionals to applying technical talents, and by coupling highly qualified personnel training, applied research and social services with local industrial structures and technological structures, and giving full play to the important role of local higher education in enhancing national competitiveness in line with the The main trends in the development of world higher education are not only the important content of the construction of the connotation of local undergraduate colleges but also an important way for the structural adjustment of China's higher education [3].

Due to the short history of running a school and the lack of state-specific guidance and policy support, local undergraduate colleges have led to the unidentified orientation and convergence of objectives, the neglect of the practical application of theoretical knowledge, the mechanical copying of key teaching modes and contents in colleges and universities, the low quality of personnel training and the employment of students A serious crisis has occurred. Take Hubei Province as an example. In 2014, there were nearly 200,000 graduates from local universities, and as of June 27, 2014, the actual employment rate of graduates was only $69.1 \%$. Local undergraduate colleges must reshape the development mode, adhere to the guidance of the scientific concept of development, and take the initiative to work closely with local governments, industries and enterprises to establish a professional system of closely linked industrial chains and build a talent cultivation program featuring distinctive technical features. Development highlights the regional, symbiotic, applicability and other characteristics. Therefore, the transformation and development of local undergraduate colleges are not only the realistic requirements of the current social and economic transformation and upgrading, but also the important driving force for realizing its sustainable development.

\section{Local undergraduate colleges and universities transition to the plight of technology}

Local colleges and universities are often upgraded from normal colleges and vocational technical colleges. As an important part of China's higher education, it has the characteristics of running 
schools with local investment, local management and service. However, due to the lack of strategic research on long-term planning, policy support and promotion, there are many difficulties in the transition to the University of Applied Sciences. Local undergraduate colleges generally operate in accordance with the management system of "co-management of provinces and cities and market-based management". Due to the unclear management authority, the provincial government should have no management authority and place it in a state of long management and unmanaged management Embarrassing situation. From the perspective of internal management system, the academic power is weakened, the administrative power is increasingly strengthened and the constraints are lost, and the democratization and scientification of decision-making are ignored. This has seriously dampened the initiative and creativity of teachers. From external policy support, some projects and policies at the national and provincial levels mainly benefit key universities and local undergraduate colleges can hardly benefit from it. Coupled with the traffic congestion, poor information, and lack of access to other social resources, the total amount of financial support for cities and cities is seriously insufficient. In particular, the huge debts that the government owes to the construction of this huge amount of debt have made the present inadequate financial resources even more stretched [3]. The lack of funds for running a school and the lack of teaching hardware directly restrict the quality of personnel training and the ability to serve localities and fail to form the characteristics and vitality of running schools.

Affected by the inertia of elite education, many local undergraduate colleges consider undergraduate education as academic education. In the orientation of development, there appear unhealthy tendencies of "climbing up, seeking big, seeking for completeness, being famous, pursuing profit, convergence" and blindly expanding running schools Scale, catch up with a comprehensive university. Due to blind imitation, the eyes only stare at traditional disciplines, seldom consider regional characteristics, school conditions and market demand, unable to optimize the integration of resources, the formation of advantages and characteristics. In practice, it also seldom establishes close contact with industry and enterprises and forms a mechanism of industry-university integration. Therefore, it can not cultivate applied technical talents with both theoretical knowledge and practical ability, resulting in a large number of graduates' employment difficulties. Although the state explicitly put forward the requirements for the transformation and development of the University of Applied Sciences, there are still many local undergraduates who, after a long run, are staggering and stagnating. Due to the development difficulties, some local undergraduates have not yet reached a certain height in their understanding although they are willing to transform themselves. In practice, it is difficult to find a breakthrough in solving the problem quickly.

\section{Local undergraduate colleges and universities to transition to the path of technology}

The transformation of local undergraduate institutions is a social change that involves multiple departments and touches on various interests. As a leading force in promoting the development of economy and society and higher education, the government should strengthen administrative responsibility and ethical awareness, make overall plans and play a good role as "helm", build a public management platform, integrate goals, improve the system and plan a good working roadmap schedule. On the basis of establishing a batch of pilot institutions for transformation and development, the "Program for the Transformation of Local Universities and Colleges" was promulgated and a coalition of universities of applied technology was set up to establish a transformation management institution for local colleges and universities that is composed of government, industry and research institutes to achieve standardized management. To lead the marriage of production and learning to form a strategic alliance in such fields as personnel training, project cooperation, personnel exchanges and resource sharing. Encourage the industry, intermediaries to participate in school-level and personnel quality assessment, to build employment capacity, industrial service capacity and social contribution capacity as the key indicators of the evaluation system. The establishment of local colleges and universities to transform the development of special funds, timely solution to the development of Applied Technology University, 
some of the bottlenecks. On the basis of breaking the barriers of interests solidification, resources are mobilized to promote the transformation of local undergraduate institutions and the viability of running a school, so as to transform the universities of applied science and technology into the importance of upgrading local industries and urbanization Strategic resources to achieve the synergistic development of local undergraduate colleges and regional economy and society [4].

Enterprises are not only the creators of the real productive forces, but also the important thrust of the transformation of local undergraduate institutions. We can not just cooperate with key universities and research institutes, but also take the initiative to participate in the transformation of local institutions. Should regulate the management, improve the system to promote the integration of value, the formation of long-term mechanism to promote "school-enterprise community" sustainable development. In-depth participation in forecasting talent demand, setting up a profession with industry, formulating personnel training programs, revising teaching plans, developing professional theory and skills knowledge standards, and building a "knowledge-through-integration" curriculum system play a guiding role. Actively participate in the whole process of school management, including the selection of technical experts to undertake training courses, participate in the design of student guides, career planning and quality monitoring evaluation. Enterprises should increase scientific and technological development efforts, pay attention to scientific research cooperation, build R \& D center, key laboratories and training base to carry out cooperation projects, the implementation of knowledge and technology sharing, the formation of an important platform for knowledge accumulation and technological innovation. On the basis of following the law of growth of technical personnel, we will assist institutions to effectively integrate the transfer, production and application of knowledge so as to cultivate urgently needed high-level and high-quality applied talents for the development of local economy and society.

Local colleges and universities should do a good job system design, to comply with the academic characteristics of university organizations, adhere to democratic management and law school, play professor, expert role in school governance. First, improve the disciplinary structure. Based on the local economy and society to carry out applied research and technology research and development, and promote multidisciplinary cross-integration, strive to create a distinctive brand in some disciplines. We will promote the comprehensive reform of specialties and build a professional cluster that is relevant to the strategic emerging industries and pillar industries in the region so as to enhance the fit between the professional structure and the industrial structure. The second is the construction of double teacher. Promote young and middle-aged teachers into business plans, build a project platform for teachers, to provide opportunities for posts, keep track of developments in the academic and industry trends, improve teaching and practical ability. Third, the implementation of curriculum reform [5]. Cooperate with industry and enterprises to design curriculum, pay attention to the application of theory and advanced technology, make the course integrate more application elements, better match the professional standards, dig deep and expand practice teaching, Course content, teaching methods and evaluation of all aspects. Fourth, attach importance to foreign exchange. It is necessary to have an open mind and an international perspective. In contrast with the characteristics of the University of Applied Sciences, we should boldly learn from foreign educational concepts and mode of running schools and start cooperation with foreign universities of applied technology so as to continuously upgrade the level of running a local undergraduate university.

\section{Conclusions}

At present, there are some problems in vocational education in China, such as the low attraction, the limited level of personnel training, the lack of enthusiasm for enterprises to participate in the training of qualified personnel, the lack of close connection between vocational and higher vocational schools and the lack of funds for running schools, which seriously impede the growth of skilled personnel. The transition from a newly-built undergraduate college to a university of applied sciences is to break through the "broken road" of the modern vocational education system and 
establish a "flyover" that fits in the cultivation of high-quality skilled personnel in China's industrial economy. Therefore, such a transformation carries the dream of the country's modernization and its historic mission, which is of great significance and far-reaching significance. Of course, the current transition is only in its infancy. The "three fulfillment measures" proposed in this article are merely superficial thinking and designing of the transition start-ups and paths in the transition period. They also require the constant replenishment and improvement of practice.

\section{Acknowledgements}

Project: Heilongjiang Province Education Science "Thirteenth Five-Year Plan" key project in 2017 "Heilongjiang Province, the transformation of local colleges and universities bottlenecks in the development and countermeasures."

Project Number: GBB1317109

\section{References}

[1] Guo Guiying, Yao Lin. Research on the orientation of running a university in our country [J]. Now Generation Education Science, 2001 (4): 59.

[2] Liu Xianjun, Wu Hongfu. The Connotation, Restriction and Reform of Talents Training Mode Reform Way out [J]. Chinese Higher Education, 2009 (12): 10.

[3] Gong Yizu. A Brief Discussion on University Training Mode [J]. Higher education research, 1998 (1): 86-87.

[4] Yu Xin. The basic understanding of quality and personnel training mode [J]. Engineering Education Research, 1997 (4): 10.

[5] Wan Rong, Jin Qinxian, Liu Jia. Tsinghua University, a new model for cooperative research fund Style [J]. Chinese university science and technology and industrialization, 2006 (11): 74-75. 